\title{
THE DEVELOPMENT OF PRECISION THIN FILM RESISTORS FOR SUBMERGED REPEATER APPLICATIONS
}

\author{
D. O. SPILLER \\ ITT Components Group Europe, Film Circuit Division, Standard Telephones and Cables Limited, \\ Paignton, Devon, England
}

(Received May 10, 1977)

\begin{abstract}
The paper describes development of a low inductance thin film resistor series with a stability of $\pm 0.15 \%$ change in resistance, over a 25 year life, in a submerged repeater environment. (40\% $\mathrm{RH}$ maximum and 0 to $30^{\circ} \mathrm{C}$ ambient temperature).

It was first necessary to establish an appropriate mathematical model relating resistor stability with time and temperature. This was devised from experimental data based on measured resistor drift at various temperatures, and enabled acceleration of resistor drift to be carried out to ensure that each resistor possessed the required stability.

Deposition of a secondary nichrome layer protects the gold/nichrome interface and promotes $\mathrm{SiO}_{2}$ adhesion. This results in an improvement in the basic elevated temperature resistor stability by minimising diffusion effects of nichrome into the conductor, and protection against electrochemical corrosion as demonstrated by 10,000 hours life test at $83 \% \mathrm{RH} @ 28^{\circ} \mathrm{C}$ on $5 \mathrm{~mW}$ load and by elevated temperature tests under electrical loading.
\end{abstract}

\section{INTRODUCTION}

The paper describes the development of a thin film resistor range with a required stability of better than $\pm 0.15 \%$ change in resistance over a 25 year life in a submerged repeater environment.

The resistor requirements are listed below:

a) $>25$ year life

b) Resistance change $\ngtr|0.15| \%$

c) Ambient temperature 0 to $30^{\circ} \mathrm{C}$

d) Ambient relative humidity $\leqslant 40 \%$

e) Temperature coefficient of resistance -100 $\mathrm{ppm} /{ }^{\circ} \mathrm{C}$ to $+50 \mathrm{ppm} /{ }^{\circ} \mathrm{C}$.

It was first necessary to develop a resistor system with the required stability and an appropriate mathematical model relating resistor drift with time and temperature.

\section{FILM DEPOSITION}

Vacuum deposited nichrome with gold contacts and a $\mathrm{SiO}_{2}$ protective layer was chosen as previous experience with these materials had indicated that the required stability could be achieved. The geometry of the resistors required a resistive film of 50 to $75 \Omega / \square$ which corresponded to a film thickness of $300 \AA$ to $500 \AA$.

Gas composition in a conventional $\left(\sim 10^{-6}\right.$ Torr $)$ vacuum system varies considerably during evacuation and film deposition and has a significant effect on the final nichrome film properties e.g. stability and TCR. To achieve repeatable film properties it was necessary to determine the gases to which the deposited film was most sensitive and control the gas composition during deposition. See Figure 1.

The residual gas composition in the deposition system was analysed by a Vacuum Generators Mass Spectrometer (Micromass 2A) during a complete deposition cycle.

The vacuum system was initially evacuated to approximately $10^{-6}$ Torr and the substrates heated to $250^{\circ} \mathrm{C}$. As would be expected the major constituent after initial evacuation was water vapour. Previous experience with nichrome had demonstrated the need to have a high oxygen content in the film if high stability was to be achieved. Hence, after the initial pump down, air was bled into the system to a pressure of approximately $5 \times 10^{-5}$ Torr.

The nichrome sources, under shutters, were heated up and allowed to stabilize and then the shutters were opened and nichrome evaporated. Immediately the 


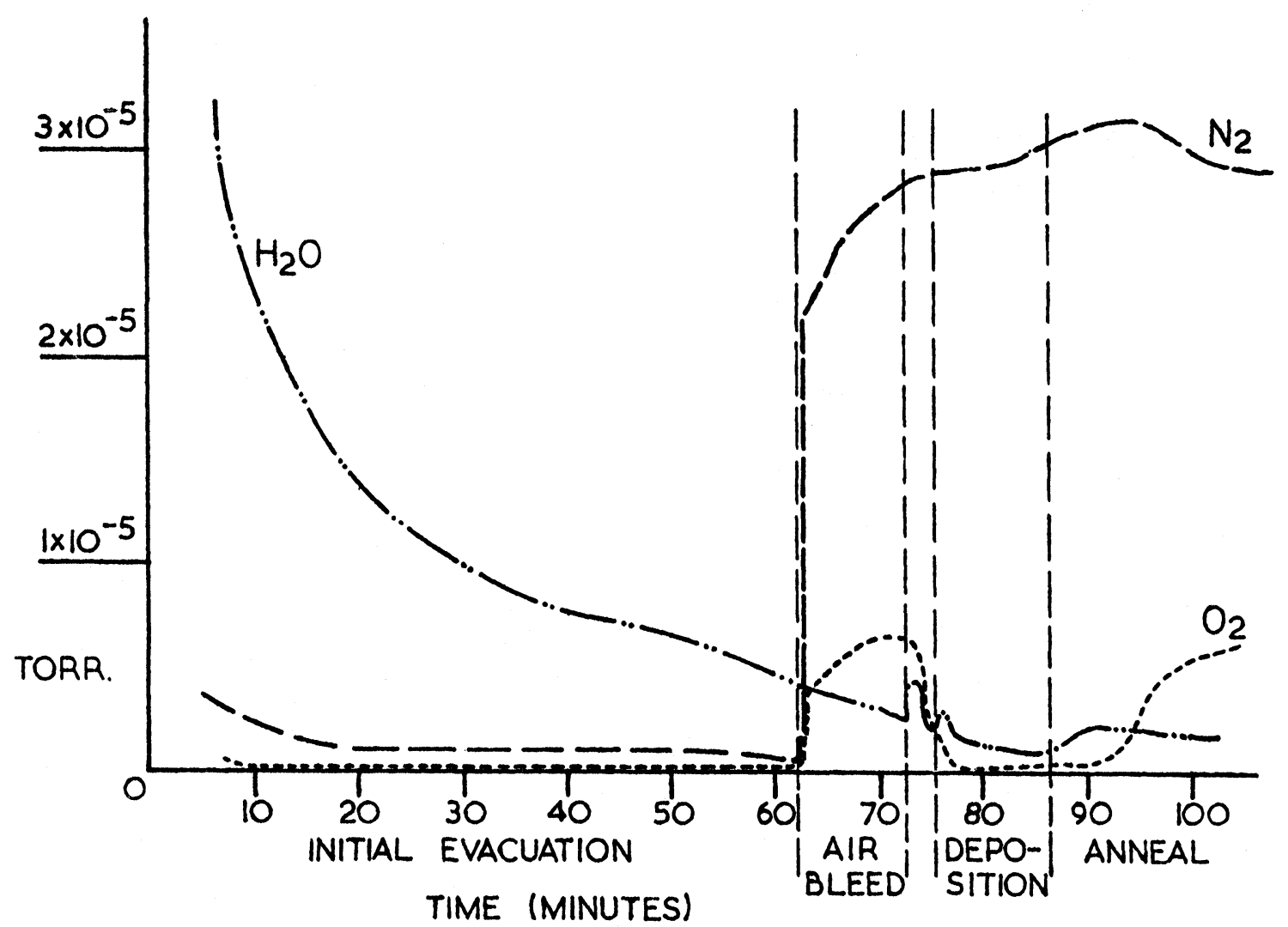

FIGURE 1 Residual gas composition during deposition.

oxygen partial pressure was reduced to approximately $5 \times 10^{-7}$ Torr.

After the deposition was completed, and the sources shut down, oxygen was still absorbed by the film and the system was allowed to reach equilibrium before the vacuum system was let up to atmosphere. Thus it is essential that an initial low base pressure is achieved and that a controlled oxygen content is maintained during deposition and annealing if repeatable resistive films are to be achieved.

Having established suitable gas pressure, temperature and anneal schedules, resistors with gold conductors were then deposited to enable resistor stability to be measured at various temperatures.

\section{RESISTOR STABILITY MODEL}

Resistor test patterns covering a range of aspect ratios were then tested using a four terminal technique at temperatures of $50,70,100$ and $150^{\circ} \mathrm{C}$ and the variation of resistance with time, plotted (Figure 2).
The change of resistance was then plotted against the reciprocal of temperature for a specific time. (See Figure 3).

The straight line relationship indicates a drift mechanism with an activation energy of $0.33 \mathrm{eV}$ which is comparable to the activation energy of chromium films ${ }^{1}$ (0.24 to $\left.0.34 \mathrm{eV}\right)$.

Thus an expression can be derived for the change of resistance with time and temperature of the form:

$$
\begin{aligned}
\Delta R & =\% \text { change of resistance } \\
\Delta R=A\left[\exp ^{-E} / T\right](t)^{1 / 2} \quad T & =\text { absolute temp. }{ }^{\circ} \mathrm{K} \\
t & =\text { hours on test } \\
A & \text { and } E \text { are constants }
\end{aligned}
$$

Using this expression the predicted resistor drift after 25 years at a temperature of $30^{\circ} \mathrm{C}$ would be $0.05 \%$. Thus:

1) The nichrome film is sufficiently stable.

2) The film can be pre-aged to improve subsequent stability. 
3) The stability and hence acceleration factors can be predicted from the formula and accelerated life tests can be carried out to simulate the 25 year life.

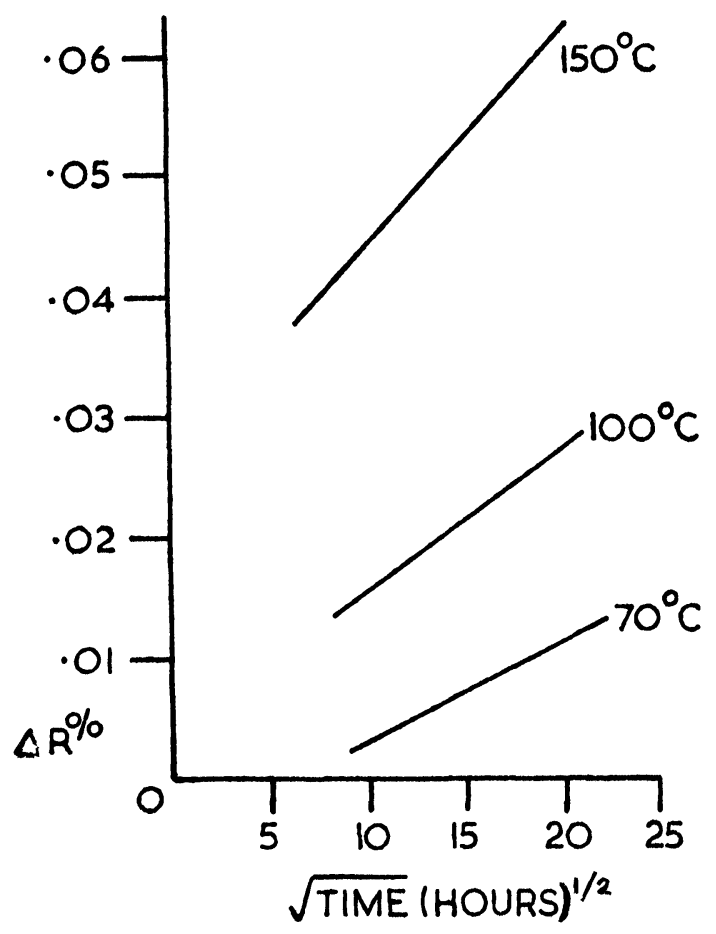

FIGURE 2 Variation of resistor value with time.

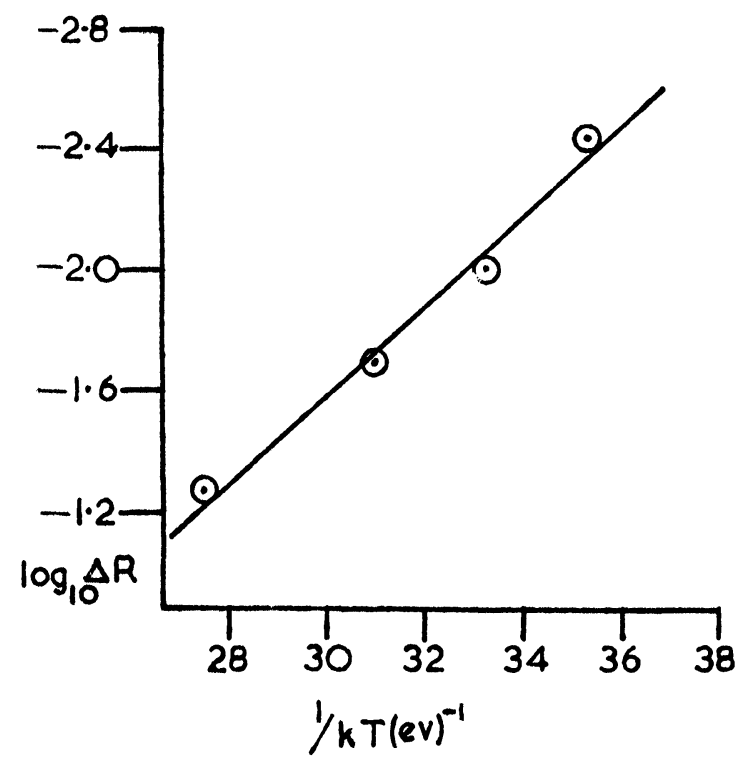

FIGURE 3 Variation of resistor value with temperature.

\section{ENVIRONMENTAL EFFECTS}

The resistor construction with gold conductors meant that dissimilar metals were present at the conductor/ resistor interface and this indicated that these resistors could be humidity sensitive when operating at low electrical power. This was in fact the case, although the early results obtained were extremely variable i.e. some resistors, under power $(<10 \mathrm{~mW})$

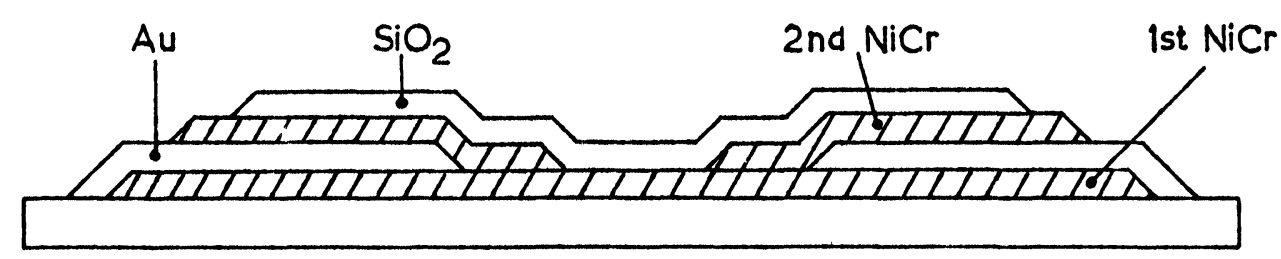

DOUBLE NICHROME CONSTRUCTION

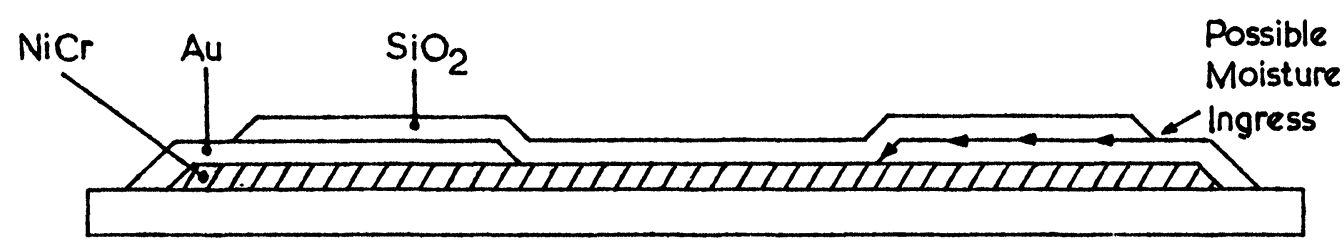

SINGLE NICHROME CONSTRUCTION

FIGURE 4 Nichrome construction. 


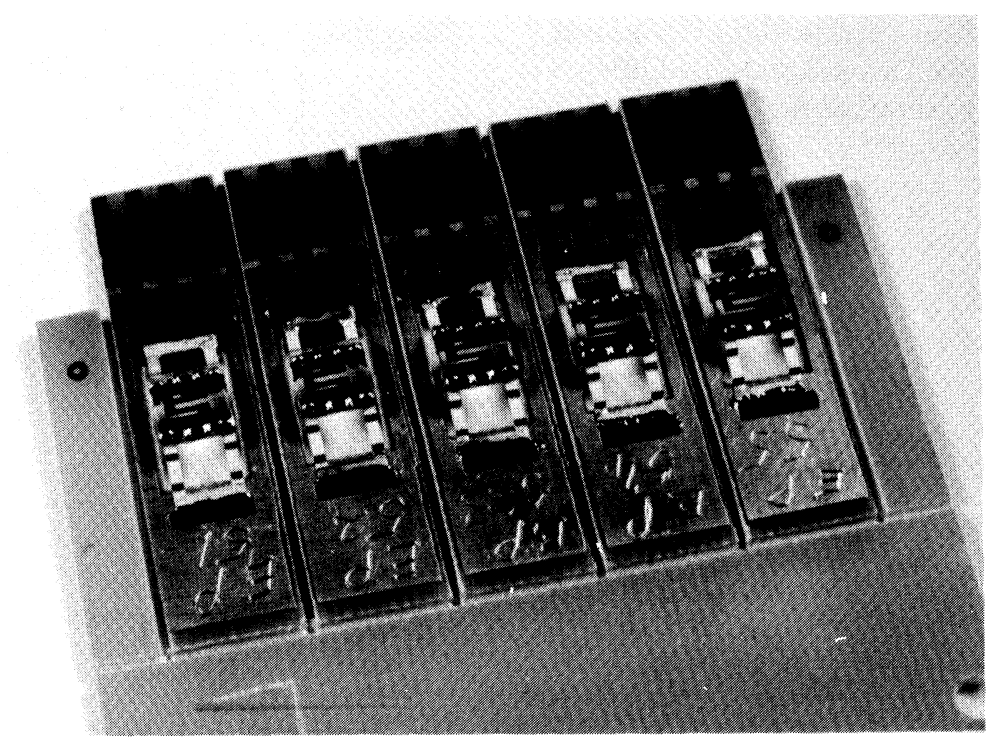

FIGURE 5 Adjusted resistors (dimensions of each circuit substrate $5 \mathrm{~mm} \times 5 \mathrm{~mm}$ ).

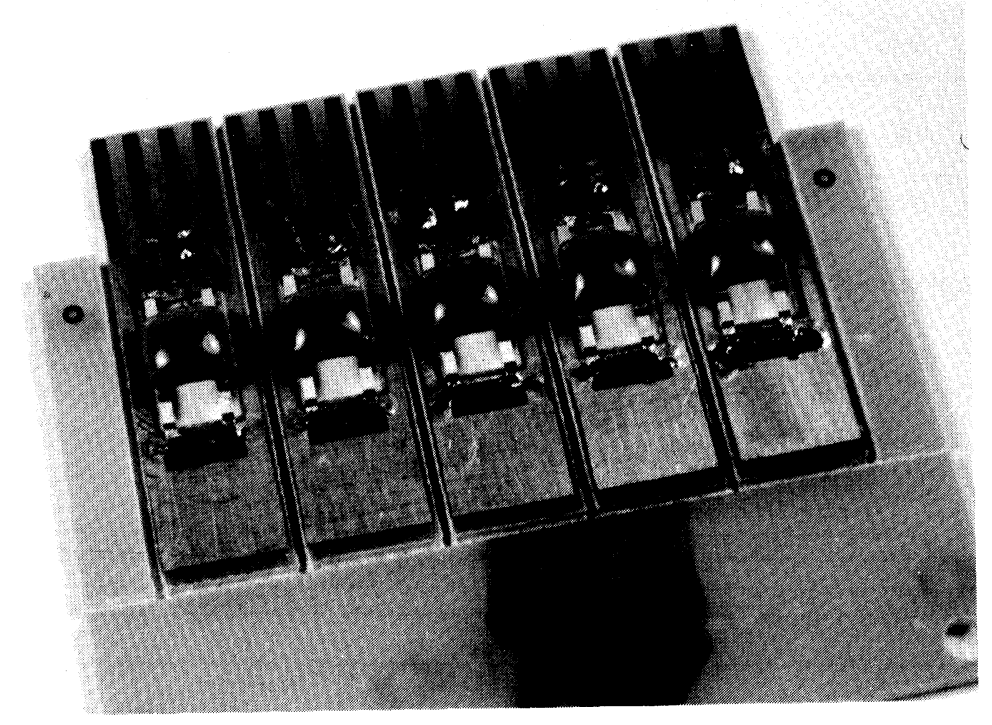

FIGURE 6 Adjusted and resin encapsulated resistors (dimensions of each circuit substrate $5 \mathrm{~mm} \times 5 \mathrm{~mm}$ ).

with a high humidity environment (95\% RH @ 40 $\left.{ }^{\circ} \mathrm{C}\right)$ showed no measurable drift and others drifted rapidly after a short period of time.

To eliminate this effect a second nichrome layer was deposited over the conductor/resistor interface. See Figure 4. This improved the resistor performance in several ways.

1) The sensitive $\mathrm{Au} / \mathrm{NiCr}$ interface is now trans- ferred onto the conductor and hence any changes to the $\mathrm{NiCr}$ here would have an insignificant effect on the resistor value.

2) $\mathrm{The} \mathrm{SiO}_{2}$ layer bonds chemically to the $\mathrm{NiCr}$ and thus the interface region is effectively sealed. With a single NiCr layer it is possible for moisture to migrate along the $\mathrm{Au} / \mathrm{SiO}_{2}$ interface to the resistor/ conductor interface. 


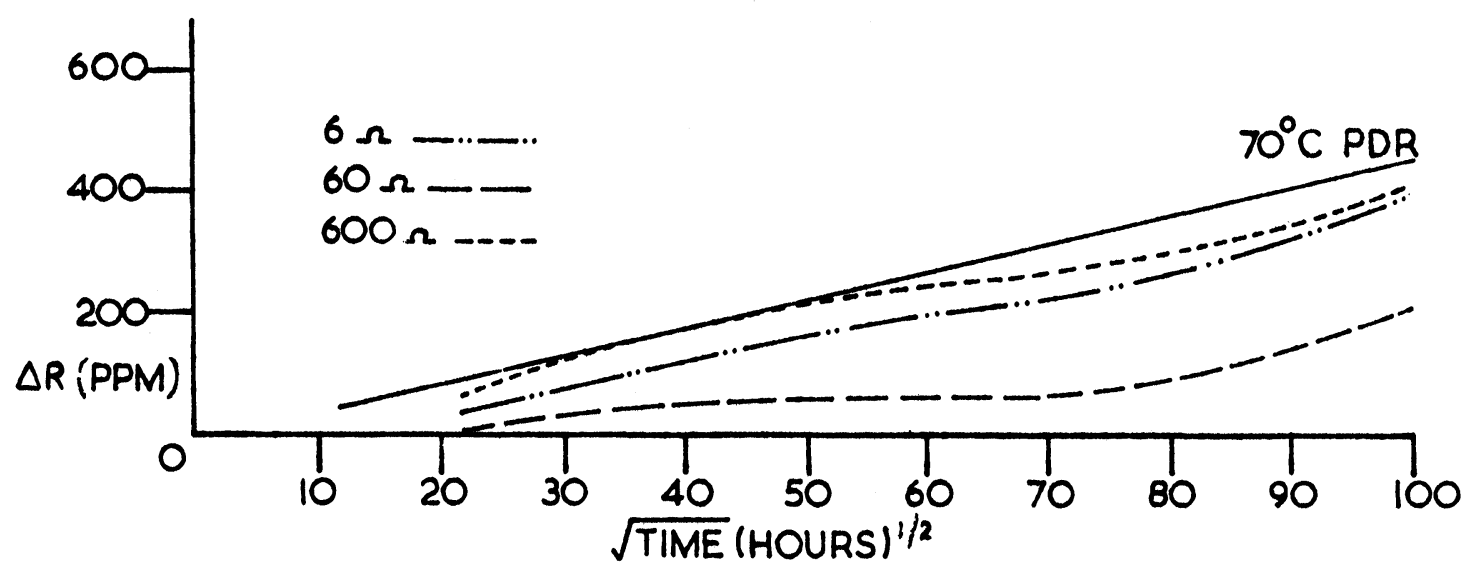

FIGURE 7 Resistor drift at $70^{\circ} \mathrm{C}$ with $5 \mathrm{~mW}$ load.

3) During successive stabilisation bakes of the resistor, $\mathrm{NiCr}$ diffuses into the gold, reducing the $\mathrm{NiCr}$ thickness locally which also increases the resistors sensitivity to moisture. The application of the second $\mathrm{NiCr}$ layer eliminates this problem.

Based on the preceding results the following resistor construction was adopted:-

1) Vacuum deposition of the following materials onto glass substrates through metal masks.
a) $\mathrm{NiCr}$, b) $\mathrm{Au}$, c) $\mathrm{NiCr}$, d) $\mathrm{SiO}_{2}$

This is followed by a stabilisation bake in air.

2) The glass plates are scribed and broken out to produce discrete resistor chips. These are inspected and resin bonded and soldered into lead frames, cleaned and attached to PCB's. This enables accurate resistance measurements to be carried out during the later stages of manufacture.

3) The resistors are then adjusted using a pulsed YAG laser to remove areas of the nichrome film (Figure 5).

4) The resistors are resin encapsulated to give them some degree of mechanical protection during handling (Figure 6).
5) The resistor TCR, value and stability are measured and recorded.

\section{RESISTOR QUALIFICATION}

The resistors were qualified under the following conditions:

1) $10 \mathrm{~K}$ hours@ $5 \mathrm{~mW}$ d.c.in a $70^{\circ} \mathrm{C}$ ambient. This is equivalent to 25 years at $30^{\circ} \mathrm{C}$, determined from the stability formula, i.e. the required life of the resistor. The results achieved are shown in Figure 7. The drift rates closely follow the drift rate predicted from the formula at $70^{\circ} \mathrm{C}$.

2) $10 \mathrm{~K}$ hours@ $90 \mathrm{~mW}$ d.c. and a.c. in a $85^{\circ} \mathrm{C}$ ambient. This resistor film runs at a measured temperature of $100^{\circ} \mathrm{C}$ and the test is equivalent to 10,000 hours @ $100^{\circ} \mathrm{C}$. The results are shown in Figure 8. The drift rates are less than those predicted for a film at $100^{\circ} \mathrm{C}$ and confirm that there is no electrical field effect on the resistor stability.

3)10K hours @ 5, 45 and $90 \mathrm{~mW}$ a.c. and d.c. in an ambient of $28^{\circ} \mathrm{C}$ with a relative humidity of $83 \%$. The results are shown below and confirm that the

\begin{tabular}{lllllll}
\hline & $\begin{array}{l}\text { Predicted } \\
\text { drift } \\
10 \mathrm{~K} \text { hours } @ 28^{\circ} \mathrm{C}\end{array}$ & $\begin{array}{l}\text { Measured } \\
\text { drift } \\
5 \mathrm{~mW} \text { d.c. }\end{array}$ & $\begin{array}{l}\text { Measured } \\
\text { drift } \\
5 \mathrm{~mW} \text { a.c. }\end{array}$ & $\begin{array}{l}\text { Measured } \\
\text { drift } \\
\mathbf{4 5 \mathrm { mW } \text { d.c. }}\end{array}$ & $\begin{array}{l}\text { Measured } \\
\text { drift } \\
45 \mathrm{~mW} \text { a.c. }\end{array}$ & $\begin{array}{l}\text { Measured } \\
\text { drift } \\
90 \mathrm{~mW} \mathrm{d.c.}\end{array}$ \\
\hline$\Delta R$ ppm & 100 & 63 & 17 & 27 & 56 & 99 \\
\hline
\end{tabular}

Measurement accuracy \pm 80 ppm. 


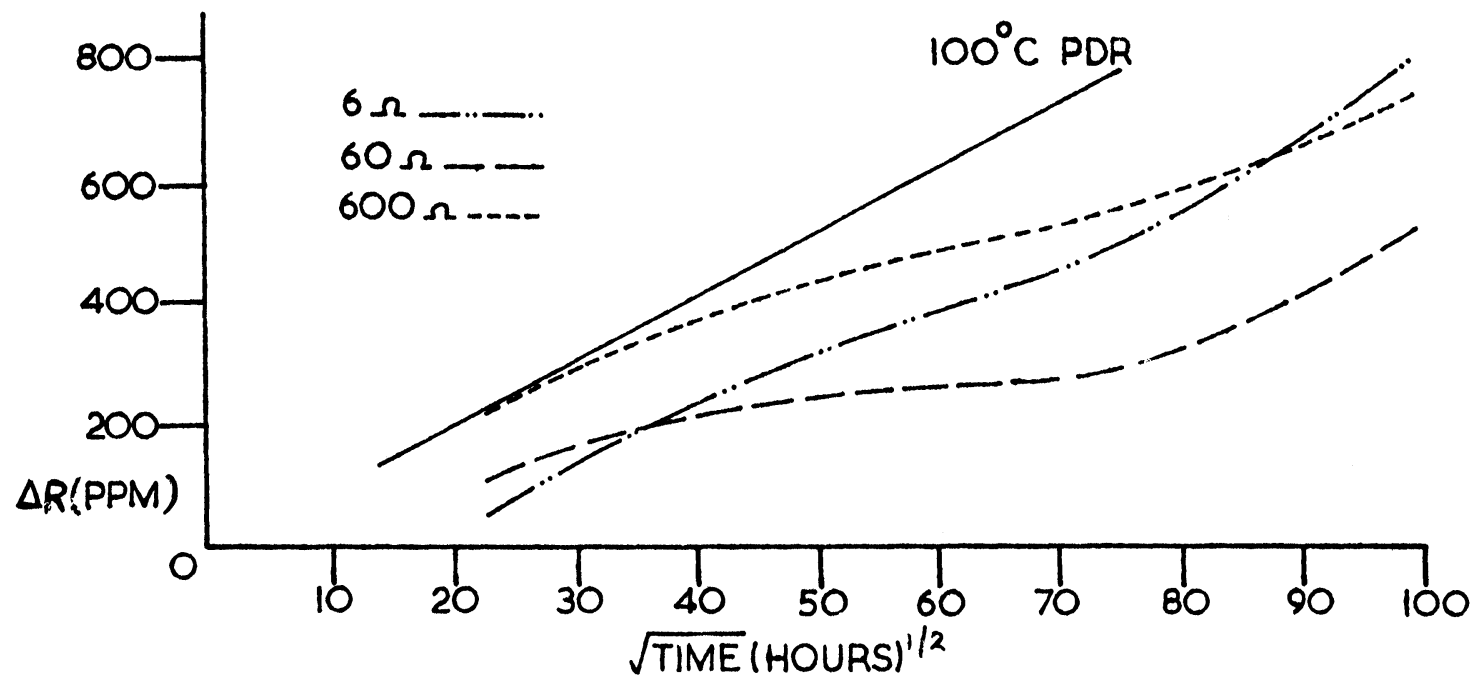

FIGURE 8 Resistor drift at $85^{\circ} \mathrm{C}$ with $90 \mathrm{~mW}$ load.

resistors are insensitive to a combination of humidity and applied voltage.

\section{CONCLUSIONS}

A resistor system has been developed. A model for relating resistor drift with time and temperature has been established and the resistors have been qualified for the required 25 year life expectancy in a submerged repeater environment. The model has been validated by the qualification results.

\section{REFERENCES}

1. W. A. Crossland, C. A. Marr and H. T. Roettgers, STL Memo No. 592. 

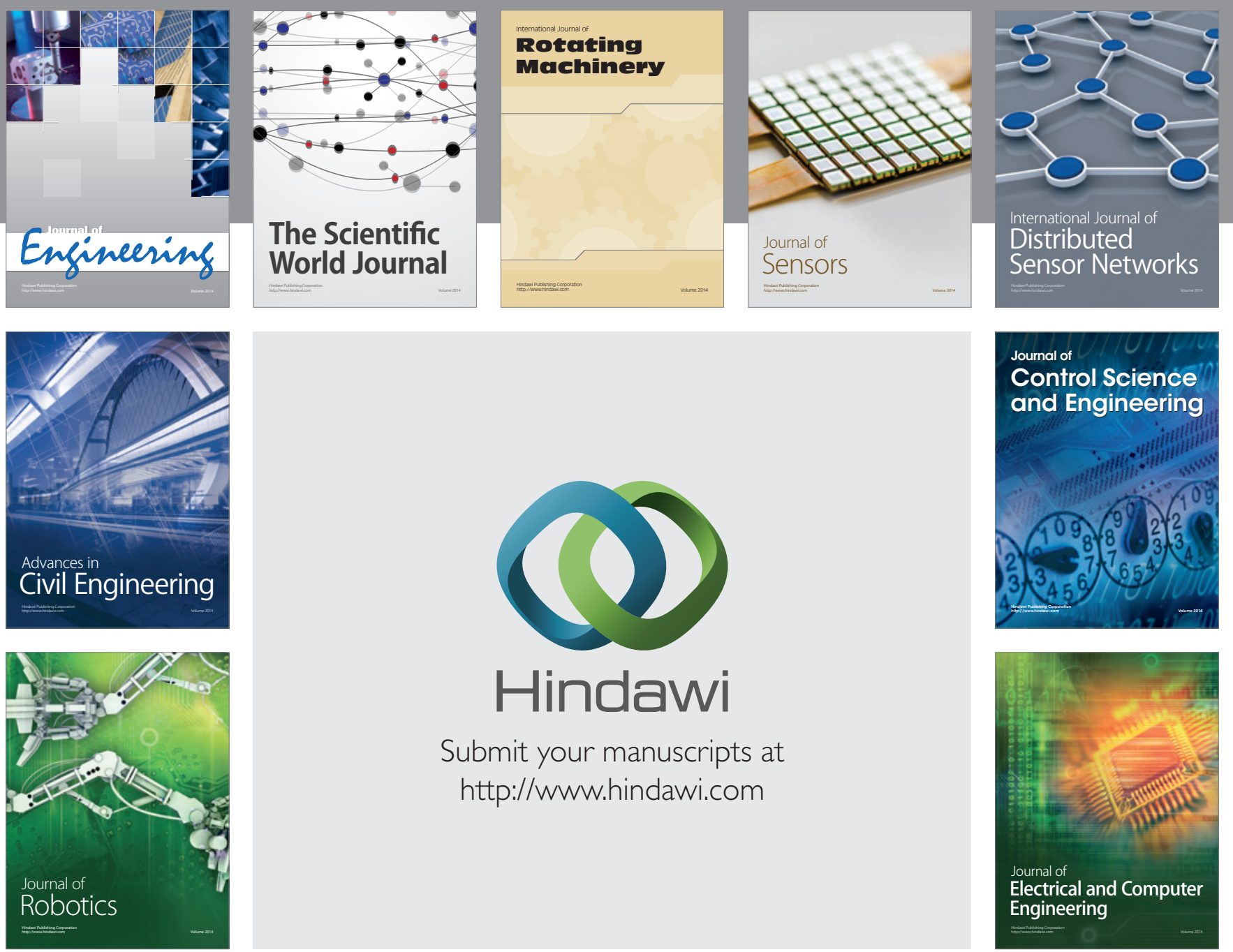

Submit your manuscripts at

http://www.hindawi.com
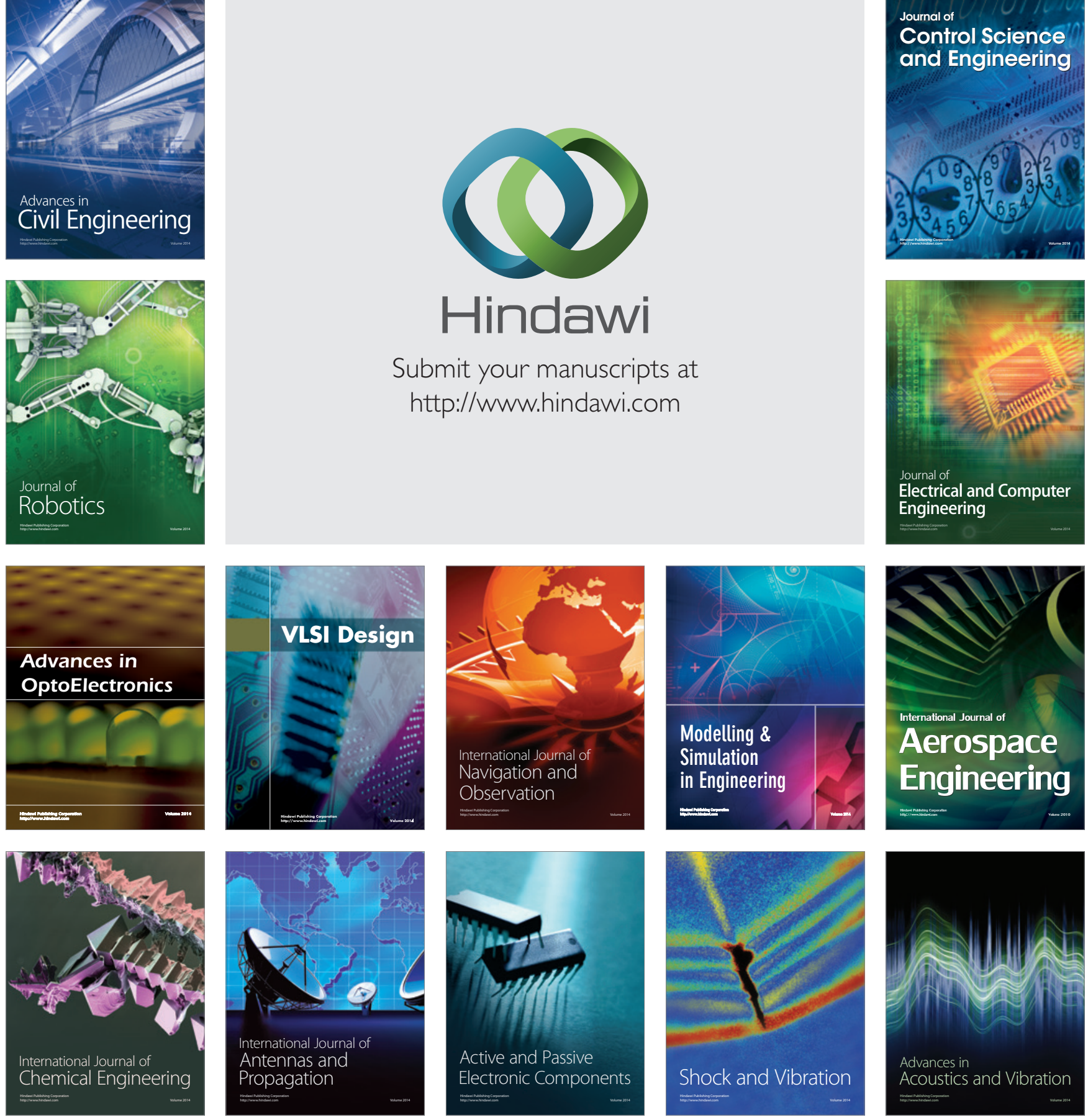